\title{
Maternidade: transformações na família e nas relações de gênero*
}

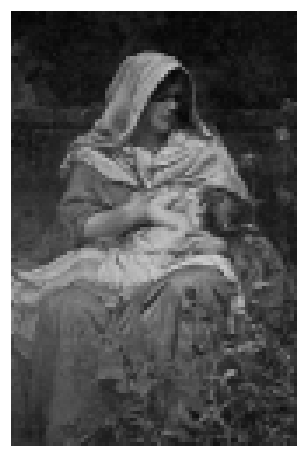

Lucila Scavone ${ }^{1}$

SCAVONE, L. Motherhood: transformation in the family and in gender relations. Interface _ Comunic, Saúde, Educ, v.5, n.8, p.47-60, 2001.

This article makes a sociological reflection on the most striking changes in the patterns and experiences of contemporary motherhood, based on existing studies and research, trying to place the debate surrounding this process. It assumes that choosing motherhood is a modern phenomenon consolidated in the course of the twentieth century as a result of the progress of industrialization and urbanization. With increased access to formal education and professional training, women will tend to take up positions in public space, while remaining responsible for raising their children, which turns motherhood into a reflexive choice, enabled by modern contraception (and conception). This choice, however, is marked by the relations of class, race and ethnic background, and gender. The article concludes that we are currently experiencing a transition period toward a new model of family and motherhood, whose basis it the ideal of equally balanced parental responsibility that, despite some progress, is still far from having been attained.

KEY WORDS: motherhood, gender, family.

Este artigo faz uma reflexão sociológica das mudanças mais marcantes nos padrões e experiências da maternidade contemporânea, com base em estudos e pesquisas existentes, buscando situar o debate que tem sido construído em torno desse processo. Pressupõe que a escolha da maternidade é um fenômeno moderno consolidado no decorrer do séc. XX com o avanço da industrialização e da urbanização. Com mais acesso à educação formal e à formação profissional, as mulheres vão ocupar o espaço público, mantendo a responsabilidade da criação do(a)s filho(a)s, o que fez a maternidade se tornar uma escolha reflexiva, possibilitada pela contracepção (e concepção) moderna. Entretanto, essa escolha é marcada pelas relações de classe, de raça/etnia e de gênero. Conclui que estamos vivendo um período de transição para um novo modelo de família e maternidade, cujo substrato é o ideal de eqüidade na responsabilidade parental que, apesar dos avanços, ainda está longe de ser alcançado.

PALAVRAS-CHAVE: maternidade, gênero, família.

\footnotetext{
* A primeira versão deste texto foi apresentada no GT Família e Sociedade na XIX Reunião Anual da ANPOCS, Caxambu, MG, 1995.

${ }^{1}$ Departamento de Sociologia, Universidade Estadual Paulista/UNESP, Campus de Araraquara. <lucsca@uol.com.br>
} 
Introdução

O objetivo deste artigo é fazer uma reflexão sociológica das mudanças mais marcantes nos padrões e experiências contemporâneas da maternidade, com base em estudos e pesquisas existentes, situando o debate teórico em torno desse processo (Badinter,1980; Chodorrow, 1980; Deutsch,1987; Ferrand, 1982; Knibielher, 1977; Kitzinger, 1978; Vilaine et al., 1986). Pressupomos que a escolha da maternidade é um fenômeno moderno consolidado no decorrer do séc. XX com o avanço da industrialização e da urbanização.

As transformações pelas quais os padrões de maternidade vêm passando, nos últimos trinta anos, devem ser pensadas em conexão com esses processos sociais e com a globalização econômica, a qual contribuiu para acelerar a difusão de novos padrões de comportamento e consumo. Entre estes, podemos citar como exemplo, o consumo crescente das novas tecnologias reprodutivas (contraceptivas e conceptivas) que ofereceram às mulheres, da década de sessenta em diante, a possibilidade de escolher com maior segurança a realização da maternidade.

Cabe lembrar, neste decurso, as mudanças que vêm ocorrendo na vida privada, especialmente na família e nas relações de gênero, com a emergência de novos modelos de sexualidade, parentalidade e amor, tais quais os apontados por Giddens (1993, p.73) como o "amor confluente" que "presume igualdade na doação e no recebimento emocionais", fruto das relações de gênero observadas, em pesquisas analisadas por este autor, nas sociedades inglesa e americana, nas décadas de setenta e oitenta.

Neste artigo abordamos a maternidade como um fenômeno social marcado pelas desigualdades sociais, raciais/étnicas, e pela questão de gênero que lhe é subjacente. Decorre disto que as mudanças e implicações sociais da realização dessa experiência não atingem da mesma forma todas as mulheres, países e culturas, apesar de existir um modelo de maternidade preponderante nas sociedades ocidentais contemporâneas, que tem como características gerais proles reduzidas e mães que trabalham fora ${ }^{2}$.

Portanto, é necessário considerar neste debate a inserção das mulheres no mercado de trabalho, sua presença no mundo público e os impactos que estes fatos trouxeram à instituição familiar e, em conseqüência, à

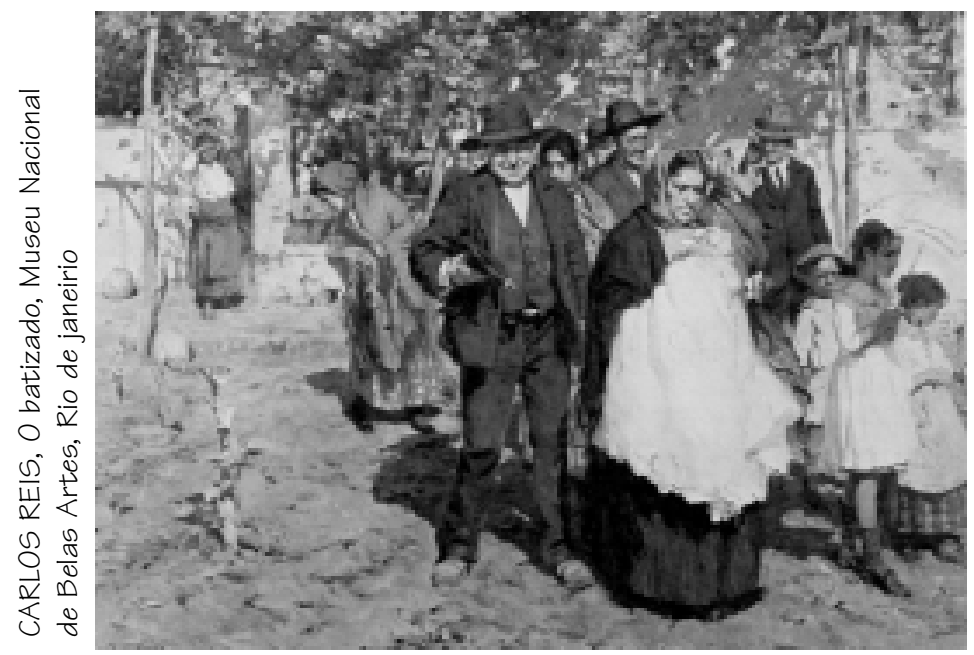
experiência da maternidade. O pano de fundo desta discussão ressalta que a questão da maternidade em todos seus aspectos sempre esteve presente na luta libertária das mulheres e, portanto, foi objeto constante da reflexão teórica feminista. É com base nestes elementos que construímos nossa reflexão sobre a maternidade.
${ }^{2}$ As diferenças do modelo dominante de maternidade são observáveis nas variações das taxas de fecundidade em diferentes países. Ela costuma ser mais alta nos países menos desenvolvidos, onde as políticas de controle da natalidade ainda estão em curso ou naqueles países que, por motivos culturais, sociais $e$ econômicos estas políticas não vingaram como na maioria dos países africanos (George, 1990).

Entretanto, segundo Leridon e Toulemon (1996), a taxa mundial de fecundidade em 1991 era de um pouco mais de três filho/as por mulher, indicandonos que a tendência da maternidade futura será de proles reduzidas. 
${ }^{3}$ A realização da maternidade não era especialmente aconselhada às mulheres

trabalhadoras: as vendedoras nas lojas de departamentos em Paris, na segunda metade do séc. XIX temerosas de perder o emprego, costumavam amarrar a barriga para esconder a gravidez, o que resultava, seguidamente, em perda da criança (Zola, 1998).

${ }^{4}$ Veja-se entre as análises brasileiras sobre mulheres $e$ trabalho Bruschini (1994), Abramo e Paiva Abreu (1998). Sobre emprego e estratégias familiares na França e Brasil ver Cahiers du GEDISST (1992). O feminismo de inspiração marxista utilizou muito o conceito de "dupla jornada" para designar o trabalho da mulher operária na fábrica $e$ em casa. Este último também foi chamado de "trabalho invisíve". Ver Larguia (1970).
Ser ou não ser mãe: dilema moderno?

Nas sociedades rurais, a maternidade sempre foi assimilada à fecundidade da terra. As crianças apareciam como necessárias para o trabalho e como segurança para o futuro dos pais, na velhice e na doença, embora, muitas vezes, representassem um encargo no presente (Knibielher, 1977). O "infanticídio tolerado" a que se refere Ariès (1981), no final da Idade Média, retrata uma época na qual a vida da criança e a própria experiência da maternidade tinham outro valor.

Segundo Giddens (1993) a "invenção da maternidade" faz parte de um conjunto de influências que afetaram as mulheres a partir do final do séc. XVIII: o surgimento da idéia de amor romântico; a criação do lar, a modificação das relações entre pais e filhos. O autor assinala que no final do séc. XIX houve um "declínio do poder patriarcal" com o "maior controle das mulheres sobre a criação dos filhos" referindo-se a um deslocamento da "autoridade patriarcal para a afeição maternal" (Ryan 1981, apud. Giddens, 1993, p.53). Ele destaca como novo, neste período, a forte associação da maternidade com a feminilidade.

Este modelo se consolidou-se em uma ideologia que passou a exaltar o papel natural da mulher como mãe, atribuindo-lhe todos os deveres $e$ obrigações na criação do(a)s filho(a)s e limitando a função social feminina à realização da maternidade. Entretanto, como nos alerta Knibielher $e$ Fouquet (1977), a realização desse ideal de maternidade era impossível para as mulheres pobres:

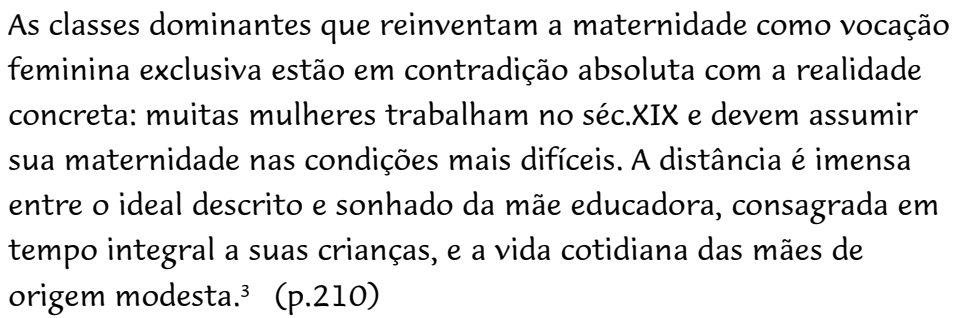

A transição de um modelo tradicional de maternidade (a mulher definida essencial e exclusivamente como mãe: proles numerosas) para um modelo moderno de maternidade (a mulher definida também como mãe, entre outras possibilidades: proles reduzidas e planejadas) deu-se com a consolidação da sociedade industrial.

As contradições inerentes ao processo de industrialização e a forma como as mulheres ingressaram no mercado de trabalho, marcadas por profundas desigualdades sociais e sexuais, revelam os impactos desse processo na mudança dos padrões da maternidade. No momento em que as mulheres das famílias operárias, no séc. XIX, começaram a associar, de forma crescente, trabalho fora do lar e maternidade (leia-se, também, como trabalho no lar), instaurou-se a lógica da dupla responsabilidade, que se consolidou no séc. $\mathrm{XX}$, com o avanço da industrialização e da urbanização, recebendo por parte das análises feministas contemporâneas a designação de "dupla jornada de trabalho" ${ }^{4}$. 
Com mais acesso à educação formal e à formação profissional, as mulheres vão, no decorrer do século $\mathrm{XX}$, ocupar gradativamente o espaço público, ao mesmo tempo em que mantêm a responsabilidade na criação do(a)s filho(a)s. Neste contexto, ser ou não ser mãe passou a ter uma dimensão reflexiva ${ }^{5}$, a ser uma decisão racional, influenciada por fatores relacionados às condições subjetivas, econômicas e sociais das mulheres $e$, também, do casal.

$\mathrm{O}$ advento da modernidade e de suas conquistas tecnológicas, sobretudo no campo da contracepção, e mais recentemente da concepção, trouxe às mulheres uma maior possibilidade na escolha da maternidade e abriu espaço para criação do dilema de ser ou não ser mãe. Um dos elementos que viabilizou a escolha da maternidade foi, sem dúvida, a contracepção moderna.

Entretanto, o controle da fecundidade (com o uso de contraceptivos e/ou abortivos) não é novo na História. Diferentes sociedades utilizaram diversas formas de evitar os nascimentos. Para Shorter (1992, p.168)

as mulheres sempre tiveram a possibilidade de acabar com uma gravidez indesejada, principalmente pelo meio de drogas abortivas. Algumas dessas drogas eram muito perigosas e precisava uma vontade firme para usá-las. Assim, o aborto foi quase sempre um ato desesperado.

Foi no final do séc. XIX que essa situação começou a mudar e segundo Shorter, acontece a "primeira grande explosão do aborto", como meio de limitar os nascimentos.

Esses fatos sugerem que a realização da maternidade não foi sempre aceita como irreversível, ocorrendo na História, em épocas distintas e por motivos diversos, uma recusa circunstancial da maternidade frente aos padrões de natalidade dominantes, sobretudo entre as mulheres solteiras el ou entre aquelas que já tinham tido muito(a)s filho(a)s. Vale dizer, a condenação social desta recusa sempre foi muito forte, ainda persistindo em sociedades nas quais o aborto é proibido.

Nas sociedades industrializadas modernas, com o advento do planejamento seguro dos nascimentos e a possibilidade de escolher o momento, retardando a idade de as mulheres terem o primeiro filho/a (Langevin, 1984), a recusa circunstancial da maternidade deu lugar à escolha da maternidade.

Os motivos da escolha da maternidade podem estar ligados a inúmeras causas que, isoladas ou conjuntas, se explicariam no ponto de interseção do biológico, do subjetivo e do social: o desejo atávico pela reprodução da espécie, ou pela continuidade da própria existência; a busca de um sentido para a vida; a necessidade de uma valorização e de um reconhecimento social (como no caso de algumas mães adolescentes, ansiosas por ocupar um espaço de maior respeitabilidade na sociedade); o amor pelas crianças; a reprodução tradicional do modelo da família de origem, entre outros.

Em relação aos fatores especificamente sociais estão as condições econômicas e culturais das famílias; os projetos e possibilidades profissionais
${ }^{5}$ No sentido utilizado por Giddens (1991, p.45): "A reflexividade da vida social moderna consiste no fato de que as práticas sociais são constantemente examinadase revisadas à luz de novas informações sobre estas próprias práticas, alterando constitutivamente seu caráter". 
${ }^{6} \mathrm{O}$ declínio progressivo da fecundidade, mediante utilização de métodos contraceptivos modernos, alterando o perfil demográfico da população brasileira, coincide com as transformações que resultaram dos processos de industrialização e urbanização no país, os quais possibilitaram a introdução e aceitação de novos padrões de reprodução e consumo próprios dos países do norte. Este fato está igualmente associado aos objetivos dos países credores em reduzir o crescimento

demográfico dos países devedores, no quadro dos planos de ajuste estrutural definidos pelo Fundo Monetário Internacional, quando da concessão de empréstimos ao Brasil. (Scavone, Brétin,

Thébaud-Mony, 1994) A BEMFAM, Sociedade do Bem-Estar Familiar, entidade sem fins lucrativos financiada pela IPPF (Federação de Planejamento Familiar Internacional) que subvenciona programas de planejamento familiar nos países do sul, é um bom exemplo desta política. Ela foi uma das entidades que mais contribuiu para a divulgação e distribuição dos contraceptivos orais no Brasil, atuando inicialmente no

Nordeste e,

posteriormente, no

Sudeste. Desde sua

instalação no Brasil, em

1965, a BEMFAM

realizou convênios com

prefeituras, empresas,

órgãos estaduais $e$

federais, evidenciando a política de "laissez faire" que o governo brasileiro adotou em relação ao controle da natalidade no país. (World Bank, 1990). Nos anos mais recentes a BEMFAM vem realizando surveys nacionais sobre a situação da Saúde Reprodutiva das mulheres brasileiras (BEMFAM/IRD, 1987 e 1997). das mulheres. As facilidades ou as dificuldades variam de uma classe para outra e de país para país: a situação $e$ a qualidade dos serviços públicos e/ ou particulares disponíveis; o apoio ou proximidade da família extensiva; as redes de solidariedade femininas. Entretanto, as condições materiais de existência não determinam, via de regra, a escolha da maternidade, embora elas definam as características $e$ as possibilidades desta escolha.

Foi com o advento da contracepção medicalizada moderna, especialmente da pílula contraceptiva, que as mulheres tiveram acesso a uma das principais chaves para a livre escolha da maternidade, com a possibilidade de um controle eficaz e socialmente aceito da fecundidade. Embora o direito à contracepção livre e gratuita tenha sido uma das reivindicações mais importantes do movimento feminista contemporâneo, sobretudo o europeu, ele nem sempre foi produto de uma conquista das mulheres, especialmente nos países do sul.

As formas diferenciadas da difusão dos métodos contraceptivos em diferentes países - seja como conquista de uma luta feminista (o caso da França), seja como objetivo das políticas demográficas (o caso do Brasil) indicam a existência de inúmeras contradições nesse processo ${ }^{6}$. Destaca-se entre estas, os limites da livre escolha marcados: pelas contradições de classe, raça/etnia; pelos impactos da utilização de métodos contraceptivos pesados como a esterilização feminina no Brasil; pelos danos que os métodos contraceptivos, sem acompanhamento médico, podem causar à saúde das mulheres; pelas desigualdades sociais relacionadas com o uso

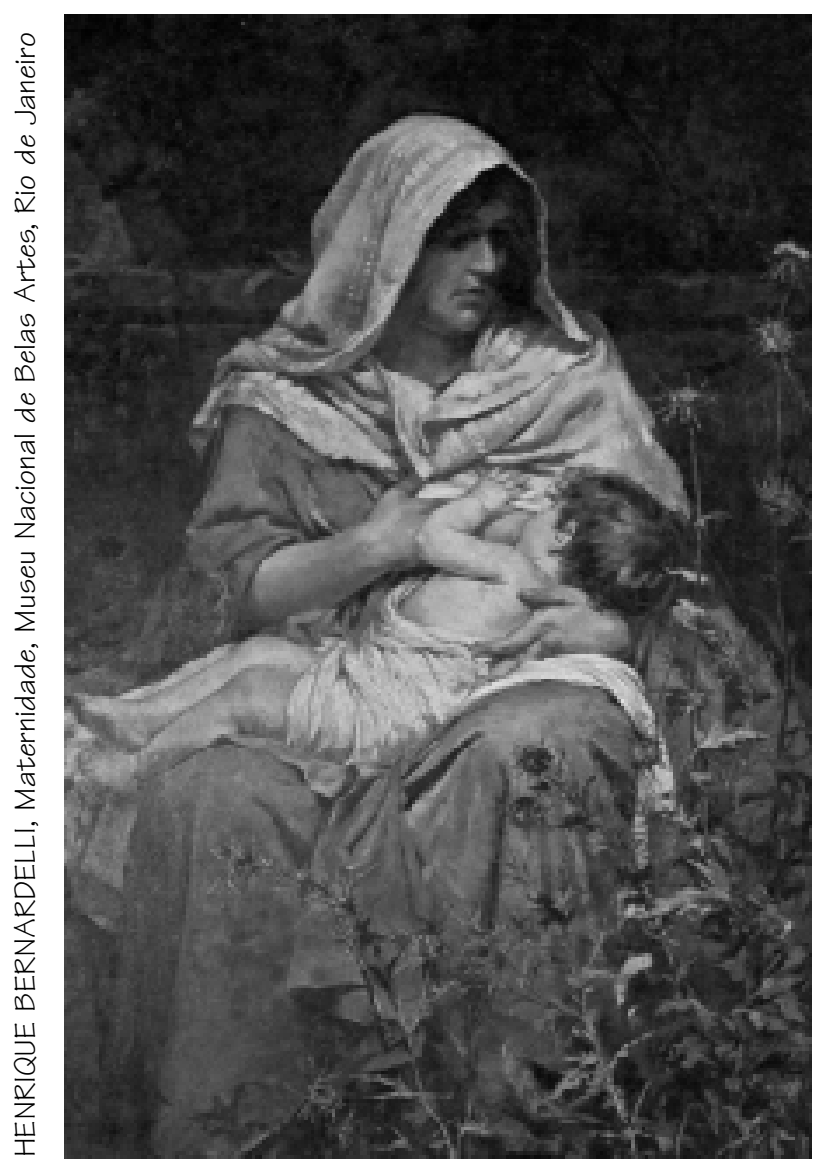

fevereiro, 2001 
dos métodos contraceptivos (Scavone; Brétin; Thébaud-Mony, 1994). Cabe ressaltar que a esterilização se tornou a solução das mulheres brasileiras ( $e$ latino-americanas) para optarem pela não-maternidade ${ }^{7}$.

A legalização do aborto, em diversos países do hemisfério norte, também foi um elemento a mais neste processo, oferecendo condições seguras $e$ menos culpabilizantes às mulheres para interrupção da gravidez indesejada. Em países como o Brasil, onde o aborto não é legalizado, o acesso ao mesmo é mais complexo, o que não impede que ele venha sendo amplamente utilizado ${ }^{8}$. A prática do aborto é uma outra possibilidade de escolha para a não realização da maternidade, reforçando o caráter social da maternidade $e$ sua não determinação biológica.

Os aspectos ambíguos da escolha da maternidade, relacionados com as condições sócio-econômicas e subjetivas de quem escolhe - portanto, nem sempre fácil, possível ou reflexiva - são visíveis na análise das diferentes experiências contemporâneas da maternidade que discutiremos mais adiante neste texto. A maternidade como escolha é um fenômeno moderno e contemporâneo que foi se consolidando no decorrer do século XX e a crítica feminista tem um lugar importante nesta reflexão, pois nos fornece os principais elementos para a compreensão do processo.

\section{Maternidade, Feminismo e Gênero}

A teoria feminista contribuiu para verbalizar a tomada de consciência das mulheres a respeito das implicações sociais e políticas da maternidade. $\mathrm{O}$ feminismo libertário, que politizou as relações da vida privada, valendo-se da reflexão sobre questões ligadas à esfera da vida íntima, colocou em destaque, nos anos setenta (continuando pelos anos oitenta) a discussão do significado da maternidade $e^{9}$.

Os estudos feministas de então privilegiaram a maternidade para explicar a situação de desigualdade das mulheres em relação aos homens. Por parte das correntes teóricas radicais, considerava-se a maternidade como o eixo central da "opressão das mulheres", já que sua realização determinava o lugar das mulheres na família e sociedade. Portanto, a recusa consciente da maternidade foi o caminho proposto por esse feminismo para alcançar a liberdade. Esta recusa consistia em uma tentativa de negar o fatalismo biológico feminino da maternidade, romper com o determinismo dado pela natureza, já que ele era um argumento forte para justificar as desigualdades entre os sexos. Na França, destaca-se Beauvoir

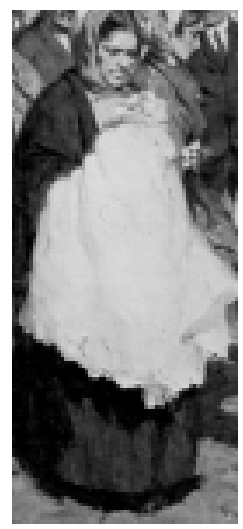
(1975, 1977), a mais expressiva expoente intelectual desta corrente. Nos EUA, uma outra corrente mais radical condicionava a libertação da mulher à chegada da reprodução artificial, supondo que, então, a maternidade não se passaria mais no corpo das mulheres (Firestone, 1976).

Já num segundo momento, uma outra corrente, inspirada na Psicanálise, recupera a maternidade como um poder insubstituível que só as mulheres possuíam - fazendo parte da história e identidade femininas - $e$ os homens invejavam (Irigaray, 1981). O problema não era mais a negação da
${ }^{7}$ De fato, a

esterilização feminina é um dos 'métodos

contraceptivos' mais utilizados nos países da América Latina

(Molina, 1999)

confirmando a

constatação de estudos

que apontam para o

fato desta técnica ser

menos utilizada no

"mundo desenvolvido"

do que no "mundo

menos desenvolvido"

(Berquó, 1999) onde a

queda da fecundidade é

considerada, pelos

organismos

internacionais, como

uma meta importante

visando ao

desenvolvimento

(Mauldin e Ross, 1991)

${ }^{8}$ Estima-se que um milhão e quatrocentos mil abortos são realizados clandestinamente por ano no Brasil. Isto significa que $6 \%$ das mulheres em idade reprodutiva realizam um aborto (The Alan Guttmacher Institute, 1994).

${ }^{9} \mathrm{O}$ slogan feminista " $O$ privado também é político" sintetiza esta politização das questões privadas, as quais foram objeto de estudo nos grupos de reflexão dos anos setenta e oitenta (Revue Partisans, 1970). A maternidade foi um dos temas

favoritos dessas discussões, conforme mostram inúmeras publicações específicas da época (Vilaine et al., 1986, entre outras). 
${ }^{10}$ A corrente alemã desse feminismo sugere às mulheres uma melhor divisão das atividades profissionais e maternais, dando maior atenção aos filhos e consumindo menos. Ver os textos de Mies (1991). Esta proposta vem ao encontro da proposta de gestão e autonomia da vida privada discutida por Gorz (1991).

${ }^{11}$ Kergoat (1996, p. 24) diz: "é impossível colocar em oposição gênero e relações sociais de sexo, os dois termos são altamente polissêmicos.

Encontramos nos dois casos, o mesmo leque de acepções que vão da simples variável mulher, até uma análise em termos de relações sociais antagônicas". 0 conceito de relações sociais de sexo é utilizado pela Sociologia francesa $e$ responde pela construção social das diferenças entre os sexos, pressupondo uma hierarquia social e uma relação de dominação e poder entre os sexos. $\mathrm{O}$ conceito de gênero, mais utilizado nos estudos de língua inglesa, também vai nessa direção, busca ultrapassar as definições da "categoria homem/ mulher como uma oposição binária que se auto-reproduz (...) sempre da mesma maneira", o que implica refutar sua construção hierárquica como natural. Além disso, a utilização deste conceito mostra que a análise deve estar voltada para: as representações simbólicas; o sentido dos símbolos e da experiência; a política institucional $e$ organizacional; a identidade subjetiva (Scoot, 1990, p.10). maternidade, mas, a divisão eqüitativa das responsabilidades entre mães $e$ pais. Segundo análise de Dandurand (1994, p.9):
As posições das mulheres sobre a maternidade se situam num contínuo entre dois pólos: um, no qual, a condição materna é vista como exasperante, exigente ou mesmo destruidora; o outro, na qual ela é apresentada como única, rica e insubstituível.

De fato, passou-se das posições que ressaltavam as implicações sociais negativas da maternidade para as que valorizavam seus aspectos psicoafetivos; de uma forte negação para uma vibrante afirmação, espelhando provavelmente as ambigüidades concretas dessa experiência. No seu conjunto, essas reflexões constituem uma crítica feminista ao discurso dominante da "invenção da maternidade". Os elementos deste contradiscurso contribuíram para maior tomada de consciência das mulheres na construção de uma escolha reflexiva da maternidade. Por outro lado, contribuíram para o questionamento mais profundo das relações de gênero na família, (re)discutindo o lugar do pai. Esta crítica foi se renovando, acompanhando as mudanças sociais e, nos anos noventa, os estudos feministas sobre a maternidade tomam uma nova direção.

Primeiramente, tornaram-se mais escassos, principalmente enquanto reflexão mais abrangente do significado da maternidade. As pesquisas do período centraram-se nas questões mais específicas dos direitos e usos das tecnologias reprodutivas, bem como de suas conseqüências à saúde das mulheres: contracepção, esterilização, aborto, cesariana, nos países do sul, $e$ novas tecnologias de concepção, nos países do norte (Dossiê Mulher e direitos reprodutivos, 1993; Akrich e Laborie, 1999). Uma das questões que surgiu dessas reflexões tem a ver atualmente com a ingerência crescente da Medicina na procriação: "a reprodução não estaria escapando progressivamente das mulheres?" (Dandurand, 1994, p.9). Esta inquietação remeteu, implicitamente, a uma postura positiva diante da maternidade: uma experiência feminina importante, cujo controle não deveria escapar às mulheres. E, por outro lado, colocou o problema da maternidade no âmbito de uma discussão mais ampla sobre os impactos das novas tecnologias nas sociedades modernas, reavivando o debate sobre a relação natureza $e$ cultura, com base no feminismo de inspiração ecológica ${ }^{10}$.

Em segundo lugar, outro grupo de estudos analisou a questão da maternidade sob o ponto de vista das relações sociais de sexo, ou de gênero ${ }^{11}$, construindo o conceito de "parentalidade": "trata-se de estudar o posicionamento dos atores sociais dos dois sexos no processo de constituição do laço parental e não mais de partir de uma especificação a priori deste laço segundo o sexo" (Combes e Devreux,1991, p.5). Este tipo de análise tem como ponto de partida a relação dos indivíduos adultos (homens e mulheres) com suas crianças, não considerando a priori as noções de maternidade e paternidade. Esses estudos constataram ocorrências de um tipo de parentalidade em que as mulheres continuam tendo uma relação mais comprometida com os filho(a)s do que os homens (Combes $e$ Devreux,1991; Cournoyer, 1994), sendo ainda elas que assumem a maioria 
das responsabilidades parentais. Por outro lado, na pesquisa de Combes e Devreux (1991) também foi observado que alguns homens também assumiam estas responsabilidades, indicando tendências de transformações nas relações parentais e nas relações de gênero. $O$ estado atual dessas pesquisas reflete tanto as mudanças que estão ocorrendo no interior da família e sociedade, como também as ambigüidades de fundo que caracterizam a experiência da maternidade.

\section{Mudanças nos padrões da maternidade}

Analisando a experiência da maternidade entre as mulheres francesas, Ferrand (1994) assinala uma relação entre a idade de as mulheres terem o primeiro filho e o meio social das mesmas, constatando que as francesas têm seus filhos majoritariamente na faixa dos 25-35 anos:

\footnotetext{
o primeiro nascimento é mais adiado quanto mais elevado é o nível de formação da mãe" (..) A decisão de ter um primeiro filho às vezes é um problema de calendário; a de ter um segundo depende de outro registro. Cerca de uma mãe em seis não deseja o segundo filho, entretanto, ter dois filhos parece ser um ideal para a grande maioria dos casais. (p.83)
}

Por outro lado, o terceiro filho, incentivado pelo Estado francês visando ao aumento da natalidade, provoca geralmente "a interrupção da atividade profissional da mãe e remete a uma imagem de conotação negativa nas representações dominantes atuais: a da mulher que não trabalha fora". Mas, a autora explica que a queda de fecundidade na França nos últimos trinta anos "não deve ser interpretada como uma recusa de filho/as (...) a proporção de casais sem filhos nunca foi tão fraca" (Ferrand, 1994, p.83).

Esta situação, num país altamente industrializado e com uma política de incentivo à natalidade explícita nos dá elementos para afirmar que o padrão de maternidade reduzida na sociedade francesa traduz a escolha reflexiva das mulheres, exercendo indiretamente seus efeitos no modelo tradicional de paternidade (pai ausente) que vai sendo substituído por um modelo contemporâneo com maior participação do pai (pai presente). Destaca-se também, naquele país, o fato de que a escolha reflexiva do primeiro filho(a) apareceu influenciada pelo grau de formação da mãe e pelo seu envolvimento na carreira profissional.

Estudos demográficos já demonstraram que a tendência, em outros países da Europa Ocidental, é cada vez mais a expansão do padrão reduzido de maternidade, abaixo de dois filho(a)s por mulher (Berquó, 1999, Leridon e Toulemon, 1996).

Além disso, os próprios efeitos do processo de globalização, a busca do equilíbrio político-demográfico mundial e a rapidez com que as informações circulam, tendem a erradicar esse modelo para os países do sul, ao mesmo tempo em que as políticas natalistas tentam revertê-lo nos países do norte ${ }^{12}$.

No caso do Brasil, um dos grandes impactos dos últimos anos na família $e$ no padrão vigente de maternidade foi a queda abrupta da natalidade - o

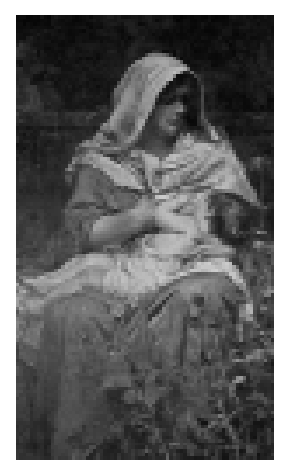

12 "A globalização não deve ser vista simplesmente como um fenômeno que "está alî", mas também como o que está aqui; ela afeta não somente espaços locais, mas afeta até as intimidades da existência pessoal, já que atua de modo a transformar a vida cotidiana" Giddens (1994, p. 11). 


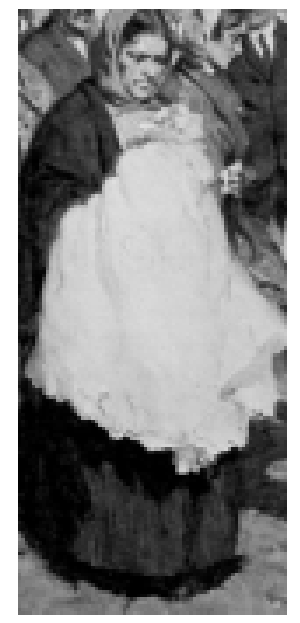

${ }^{13}$ Artigo publicado na Folha de São Paulo (14/05/95), no dia das mães, com base em dados da Fundação SEADE/1993, com o título ambígüo de

"virus da

maternidade", relata os depoimentos de

mulheres que fizeram a opção pela maternidade depois de terem conseguido uma maior estabilidade profissionale financeira. número de filho/as por mulher passou de 4,5 em 1980 para 2,5 em 1996 por meio de uma intensa política de controle demográfico, com a generalização abusiva da esterilização feminina (Nações Unidas, 1994 apud. Leridon et Toulemon, 1996; PNDS(BEMFAM, 1997). De fato, as análises das transformações da família brasileira nos últimos anos apontam para novos arranjos familiares, tais como famílias menores e aumento significativo de mulheres chefes de família (Oliveira, 1996; Goldani, 1994). Por outro lado, as mulheres brasileiras participam cada vez mais do mercado de trabalho (Bruschini,1994), confrontando e/ou conciliando a vida profissional com a vida familiar.

Se a maioria das mulheres brasileiras ainda tem seus filho(a)s na faixa etária jovem, elas também interrompem definitivamente a opção da maternidade jovens e até com poucos filho(a)s. A esterilização feminina aumenta com a idade, as mulheres jovens também usam este recurso: na Pesquisa Nacional sobre Demografia e Saúde (PNDS/BEMFAM, 1997), 11\% das mulheres, em união, até os 25 anos, são esterilizadas; dos 25 aos 29 anos, a taxa aumenta para $27 \%$, chegando a mais de $50 \%$ dos 35 aos 49 anos. Nesta mesma pesquisa, das mulheres unidas com um filho/a, $6 \%$ são esterilizadas e para as mulheres unidas com dois filho(a)s esta taxa aumenta para 42\% (PNDS, 1997).

No Estado de São Paulo, 58,4\% das mulheres têm filho(a)s entre 20-29 anos; 6,5\% têm filho(a)s entre 35-39 anos. Embora pouco representativo, o percentual dessa última faixa já demonstra um avanço na idade da realização da maternidade; em geral são mulheres profissionais que esperam primeiro alcançar uma estabilidade e independência financeira, para depois realizar a maternidade $e^{13}$. Esta é uma mudança que atinge menos as mulheres das camadas populares: em pesquisa que realizamos entre essas mulheres, no interior de São Paulo, aquelas que já tinham tido filho(as) $e$ não pretendiam mais tê-lo(as), $22 \%$ justificavam a não pretensão por considerarem que já tinham passado da idade, isto é, estavam na faixa etária entre 36-45 anos. Foi verificada, nessa pesquisa, uma relação positiva entre as mulheres que já tinham filho(a)s com a pretensão de não mais tê-lo(a)s $e$ as mulheres que não tinham filho(a)s com a pretensão de tê-lo(a)s. Destas últimas, $80 \%$ pretendiam ainda ter filho(a)s e as $20 \%$ restantes expressaram um talvez, denotando que a realização futura da maternidade estava presente nesse universo (Scavone, 1991).

Todos os indicativos acima apontados sugerem que a experiência da maternidade na sociedade brasileira está em processo de mudança, seguindo o padrão do tamanho de família vigente nas sociedades industriais avançadas (proles reduzidas e maior reflexividade na escolha) ressalvandose, porém, sua peculiaridade diante das profundas desigualdades sociais que vigoram no país. Neste contexto, tanto a possibilidade de realizar uma escolha mais reflexiva da maternidade, como a valorização da criança, varia em intensidade, de acordo com as condições sócio-econômicas-culturais de cada mulher, sugerindo as múltiplas influências nesse processo de mudança. 


\section{Impasses e Perspectivas}

Entre o modelo reduzido de maternidade com uma variedade crescente de tipos de mães (mães donas de casa, mães chefes-de-família, mães "produção independente", "casais igualitários") e as diversas soluções encontradas para os cuidados das crianças (escolas com tempo integral, creches públicas, babás, escolinhas especializadas, vizinhas que dão uma olhadinha, crianças entregues a seus próprios cuidados, avós solícitos), a maternidade vai se transformando, seguindo tanto as pressões demográficas - natalistas ou controlistas - como as diferentes pressões feministas e os desejos de cada mulher.

Se o modelo da maternidade reduzida pôde diminuir a ambigüidade entre vida profissional e vida familiar, para as mulheres ele não a esgotou. A realização da maternidade ainda é um dilema para as mulheres que querem seguir uma carreira profissional, já que são elas que assumem a maioria das responsabilidades parentais. Não seria este um dos fatores relevantes para as mulheres brasileiras recorrerem a recursos radicais como a esterilização $e$ o aborto, decidindo pela não-maternidade?

Ressalta-se, porém, que um dos aspectos mais evidentes na transformação da maternidade foi o rompimento com seu determinismo biológico. Este rompimento levou à separação definitiva da sexualidade com a reprodução, primeiro pela contracepção medicalizada, em seguida pelas tecnologias conceptivas, desconstruindo a equação mulher=mãe, $e$ construindo uma outra equação mais complexa, na qual entram em cena com maior vigor a classe médica $e$ as tecnologias.

A "maternidade artificial", ou a "parentalidade artificial" já são as fórmulas do presente (que se ampliarão no futuro) para os indivíduos estéreis que buscam a reprodução in vitro, com suas imbricadas implicações éticas, médicas, políticas, além de suas controvertidas conseqüências à saúde das mulheres (Laborie,1996). A busca pelas tecnologias conceptivas já evidencia a nova conotação da escolha da maternidade, da paternidade, ou da parentalidade: a esterilidade (por vezes causada pela esterilização precoce) pode ser resolvida pela Medicina e isto requer um longo processo, implicando uma escolha reflexiva.

Entretanto, a maternidade continua sendo afirmada como um elemento muito forte da cultura e identidade feminina pela sua ligação com o corpo e com a natureza. Essa afirmação nos países do norte constitui o que já foi conceituado como "nova maternidade", ou seja, a realização da eqüidade na responsabilidade parental (Süssmutch, 1988). Por outro lado, nesses países a maternidade tomou uma "dimensão coletiva" inegável, escapando ao individualismo familiar, a que se refere Knibielher (1977), passando a ser mais que um vínculo biológico exclusivo, com o incremento de instituições especializadas; apesar de muitas de suas implicações sociais e afetivas continuarem a constituir um conflito de gênero e entre os gêneros no interior da família. Nos países do sul, essas mudanças afetam, sobretudo, as mulheres das classes mais privilegiadas.

Em síntese, é possível observar, em relação à família e à experiência da maternidade, que estamos vivendo um período de transição para a 
consolidação de um novo modelo de maternidade, o qual tem como ideal a busca pela eqüidade na responsabilidade parental e cuja efetivação ainda está longe de ser alcançada em todos seus aspectos, já que ela pressupõe uma relação igualitária entre os sexos. Para alcançar esta eqüidade muitos elementos estão em jogo e, entre eles, a emergência de uma nova sensibilidade social que derrube o ideário do determinismo biológico.

A escolha reflexiva para aceitação ou não da maternidade (da paternidade, ou da parentalidade) constitui um elemento deste período de transição, possibilitando às mulheres $e$ aos

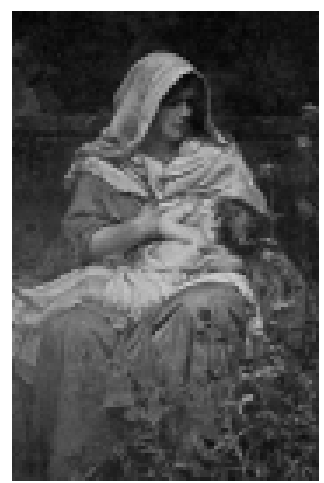
homens que a decisão pela reprodução seja feita com base na experiência adquirida, sem medo, culpa, ou qualquer sentimento de não a realização individual e/ou social. Evidentemente, esta escolha será tanto mais reflexiva quanto maior a possibilidade de acesso à informação, à cultura e ao conhecimento especializado.

Este novo modelo, que ora já se esboça, tem diversas nuanças e se define com mais ou menos força de acordo com a classe social e o país a que está referido. É o modelo: de proles reduzidas; de mulheres com carreiras profissionais; de mães e pais, juntos e/ou separados, produzindo $e$ reproduzindo; de casais hetero e homossexuais; de mães ou pais criando seus filhos sozinhos; da institucionalização dos cuidados maternos por profissionais especializados; enfim, é o modelo que busca se adequar às mudanças da vida contemporânea, ao mesmo tempo em que é forjado por estas mudanças, redesenhando o funcionamento e a estrutura da família contemporânea.

Finalmente, cabe lembrar que alguns avanços nessa transição trazem consigo novos problemas; se a possibilidade de acesso às novas tecnologias conceptivas é um recurso tecnológico que reforça a possibilidade de escolha (como costuma ser apregoado pelos seus defensores) ele cria novos impasses na realização da maternidade e nas relações familiares, cujas conseqüências sociais ainda são pouco debatidas, mas provavelmente estarão no foco das atenções dos estudos sobre família em futuro bem próximo.

\section{Referências bibliográficas}

ABRAMO, L.; PAIVA, A. A. Gênero e trabalho na Sociologia latino-americana. São Paulo: ALAST, 1998.

AKRICH , M.; LABORIE, F. De la contraception à l'enfantement. Paris: L'Harmattan, 1999.

ARIÈS, P. História social da criança e da família. Rio de Janeiro: Zahar,1981.

ARIÈS, P.; DUBY, G. Histoire de la vie privée. Paris: Seuil, 1987.

BADINTER, E. L'amour en plus. Paris: Flammarion, 1980.

BEAUVOIR, S. Le deuxième sexe. Paris: Gallimard, 1977.

BEAUVOIR, S. Et la lutte des femmes. Revue L'Arc, n.61, p.1-84, 1975.

BERQUÓ, E. A família no século XXI: um enfoque demográfico. RBEP, v.6, n.2, p.10-5, 1989.

BERQUÓ, E. Ainda a questão da esterilização feminina no Brasil. In: GIFFIN, K. (Org.) Questões da saúde reprodutiva. Rio de Janeiro: FioCruz,1999, p. 113-26. 
BRUSCHINI, C. O trabalho da mulher brasileira nas décadas recentes. Estudos Feministas, n.e., p.179-99, 1994.

CAHIERS du GEDISST. Strategies Familiales et Emploi, n.4,1992.

CHODOROW, N. Psicanálise da Maternidade. Rio de Janeiro: Rosa dos Tempos, 1980.

COMBES, D.; DEVREUX, A.M. Construire sa Parenté. Paris: CSU, 1991.

COURNOYER, M. Maternité biologique, maternité sociale. Des stratégies d'educatrices professionnelles. RF, v.7, n.1, p.73-94, Québec ,1994.

DANDURAND, R. B. Femmes et familles: sous le signe du paradoxe. RF, v.7, n.1, p.1-21, Québec, 1994.

DEUTSCH, H. La psychologie des femmes. Vol.II. Maternité. Paris: PUF, 1987.

DOSSIÊ MULHER E DIREITOS REPRODUTIVOS. Estudos Feministas, v.1, n.2, 1993.

FERRAND, M. L'appel au Désir d'Enfant dans les Discours et la Pratique dês Médecins. Les Temps Modernes, n. 1284, p.1284-1297, 1982.

FERRAND, M. A questão dos direitos reprodutivos na França. Estudos Feministas, n.e., p.79-85, 1994.

FIRESTONE, S. A dialética do sexo. Rio de Janeiro: Labor, 1976.

GEORGE, S. Conscience "Planétaire"et "Trop Nombreux" Pauvres. Le Monde Diplomatique, Paris, maio de 1990, p.4.

GIDDENS, A. As conseqüências da modernidade. São Paulo: UNESP, 1991.

GIDDENS, A. A transformação da Intimidade. São Paulo: UNESP, 1993.

GIDDENS, A. Admirável Mundo Novo: o novo contexto da política. Cad. CRH, n.21, p.9-28, 1994.

GOLDANI, A.M. As famílias brasileiras: mudanças e perspectivas. Cad. Pesq., n.91, p.7-22, 1994.

GORZ, A. Capitalisme, Socialisme, Ecologie. Paris: Galilée, 1991.

IRIGARAY, L. Le corps-à-corps avec la mère. Montreal: Pleine Lune, 1981.

KERGOAT, D. Relações sociais de sexo e divisão sexual do trabalho. In: MARQUES, L. (Org.) Gênero e Saúde. Porto Alegre: Artes Médicas, 1996. p.7-19.

KITZINGER, S. Mães: um estudo antropológico da maternidade. Portugal/Brasil: Presença/Martins Fontes, 1978.

KNIBIELHER, Y. ; FOUQUET, C. Histoire des Mères. Paris: Montalba, 1977.

LABORIE, F. Procréation artificielle: santé des femmes et des enfants. In: MASUY-STROOBANT, G. et all. Santé et Mortalité des Enfants en Europe: Inégalités Sociales D'hier et D'aujourd'hui. Paris: L'Harmattan, 1996, p.477-500.

LANGEVIN, A. Régulation Sociale du Temps Fertile des Femmes. In: Le sexe du Travail. Grenoble: PUG, 1984. p.31-41.

LARGUIA, L. Contre le travail invisible. Partisans, n.54/55, p.10-3,1970.

LERIDON, L..; TOULEMON, H. La régulation des naissances se géneralise. Les Dossiers du CEPED, n.41, p.10-14, 1996.

LES CAHIERS DU GRIF. Mères Femmes, n.17/18, Bruxelas, 1977.

MIES, M. Os modelos de consumo no Norte: causa da destruição ambiental e da pobreza no sul, Cad. REDEH, n.e., p.35-50, 1991.

MAULDIN, W. P.; ROSS, J. A. Family planning programs: efforts and results, 1982-89. Studies in Family Planning, v.22, p.350-67, 1991.

MOLINA, A. Anticoncepción, salud reproductiva y ética. In: SCAVONE, L. (Org.) Género y salud reproductiva en América Latina. Costa Rica: LUR/UNESP, 1999, p. 87-120.

OLIVEIRA, M. C. A família brasileira no limiar do ano 2000. Estudos Feministas, v.4, n.1, p.55-63, 1996.

PNDS (Pesquisa Nacional Demografia e Saúde). BEMFAM (Sociedade civil pelo bem-estar familiar no Brasil), p.48-69, 1997. 
REVUE PARTISANS. Libération des Femmes/Année Zero, n.54/5, 1970.

SCAVONE, L.; BRÉTIN, H.; THÉBAUD-MONY, A. Contracepção, Controle Demográfico e

Desigualdades Sociais: análise comparativa franco-brasileira. Estudos Feministas, v.2, n.2, p.357-72, 1994.

SCAVONE, L. Saúde das Mulheres numa cidade do interior paulista. Relatório de Pesquisa, UNESP, 1991.

SCOOT, J. Gênero: uma categoria útil de análise histórica. Educ. Realid., v. 2, n. 16, p. 5-22, 1990.

SHORTER, E. Le corps des femmes. Paris: Seuil, 1992.

SÜSSMUTCH, R. A nova maternidade e os projetos de vida da mulher. In: SOLIZ, N. (Org.) A mulher no séc. XXI. Rio de Janeiro: Instituto Goethe, 1988. p.15-28.

THE ALAN GUTTMACHER INSTITUTE. Aborto clandestino: una realidad latinoamericana. New York, 1994.

VILAINE, A.; GAVARINI, L.; LE COADIC, M. Maternité en mouvement. Grenoble/Montreal: PUG/ ESM,1986.

WORLD BANK BRAZIL. Women's Reproductive Health Report. Brasília, 1990.

ZOLA, E. Le bonheur des dames. Paris: Fasquelle, 1998.

SCAVONE, L. Maternidad: transformaciones en la familia y en las relaciones de género. Interface _ Comunic, Saúde, Educ, v.5, n.8, p.47-60, 2001.

El artículo hace una reflexión sociológica sobre los cambios más nítidos de los modelos y de las experiencias de la maternidad contemporánea. Partiendo de trabajos e investigaciones ya publicados, el estudio trata de situar el debate que esse proceso há suscitado, considerando que la elección de la maternidad es un fenómeno que se consolidó durante el siglo XX según avanzaban la industrialización y la urbanización. Gracias al mayor acceso a la educación formal y a la formación profesional, las mujeres van ocupando el espacio público a la vez que conservan la responsabilidad de educar a los hijos, con lo cual la maternidad há venido a ser una elección reflexiva, posible gracias a la contracepción y concepción modernas. Esa elección también la determinan las relaciones de clase, de raza/etnia y de género. El trabajo concluye que estamos viviendo un período de transición hacia un modelo de familia y de maternidad cuyo fundamento es el ideal de equidad en la responsabilidad de los padres, el cual, a pesar de los avances, todavía está lejos de ser alcanzado.

PALABRAS CLAVE: maternidad; género; familia. 